\title{
ИСПОЛЬЗОВАНИЕ ПОДКАСТОВ В ОБУЧЕНИИ РУССКОМУ ЯЗЫКУ КАК ИНОСЛАВЯНСКОМУ
}

В работе рассматриваются возможности использования социального интернет-сервиса подкастов в обучении русскому языку как неродному, описываются преимущества данной технологии в развитии иноязычной коммуникативной компетенции учащихся и особенности ее применения в инославянской аудитории. Учитывая, с одной стороны, отсутствие специализированных учебных подкастов по русскому языку для носителей славянских языков, а с другой - определенную близость родного и неродного языков обучающихся, в данной аудитории на продвинутом этапе целесообразно использовать аутентичные подкасты. Подкаст как источник аутентичной звучащей речи создает иллюзию естественной языковой среды и позволяет по-новому организовать работу, направленную на совершенствование навыков аудирования и говорения. Отсутствие единых требований к подкастам и контроля за соблюдением в них языковых норм, а также многочисленность и разнообразие доступных на сегодняшний день ресурсов обусловливают необходимость методических рекомендаций по выбору подкастов для определенных учебных целей и конкретной аудитории и разработки системы работы с данным ресурсом. В настоящем исследовании предложена система работы с подкастом для сербских студентов, владеющих русским языком на продвинутом уровне.

Ключевые слова: подкаст, русский язык как инославянский, аудирование, говорение, иноязычная коммуникативная компетенция

The paper considers the possibilities of using the social Internet service of podcasts in teaching Russian as a non-native language, and describes the advantages of this technology in the development of students' foreign language communicative competence, as well as features of its application to Slavic learners. Considering, on the one hand, the lack of specialized educational podcasts in Russian for native speakers of Slavic languages, and on the other hand, a certain proximity of the students' native and non-native languages, it is advisable to use authentic podcasts in this audience at an advanced stage. As a source of authentic speech, podcasts create the illusion of a natural language environment and allow us to reorganize work aimed at improving students' listening and speaking skills. The lack of uniform requirements for podcasts and control over the observance of language norms in them, as well as the abundance and variety of resources available today, necessitate the guidelines for choosing podcasts for specific educational purposes. In addition, in order to work with this resource, a specific audience and development of a system are needed. The present study proposes a podcast system for Serbian students who speak Russian at an advanced level.

Keywords: podcast, Russian as a second Slavic language, listening, speaking, foreign language communicative competence.

Информационные и телекоммуникационные технологии не только прочно вошли в нашу повседневную жизнь, но и стали неотъемлемой частью совре- 
менного образования. Процессы информатизации еще более активизировались с переходом на дистанционную форму работы. Все это обусловило регулярную интеграцию новых интернет-технологий в систему языковой подготовки обучающихся. В последние годы всё большую популярность приобретает социальный интернет-сервис подкастов.

В научной литературе используются два тесно связанных между собой термина: «подкаст» и «подкастинг». Оба термина заимствованы из английского языка, в котором они образованы путем сложения двух слов: названия торговой марки iPod, осуществляющей производство портативных медиапроигрывателей, и broadcast / broadcasting («передача, трансляция, вещание, широковещание») с усечением обеих производящих основ (Протазанова 2011; Савостьянова, Сичинава 2014).

Подкастинг - это способ передачи информации (аудиофайлов, реже видеофайлов) посредством интернета, позволяющий воспроизводить файлы на сайте, а также переносить их на другие устройства для дальнейшего использования в любое удобное для слушателя время. Последнее отличает подкастинг от других широковещательных каналов передачи информации: от теле- и радиовещания. Отдельные аудиофайлы (реже видеофайлы) или серия таких файлов, размещенных на специализированных интернет-ресурсах, называются подкастами. В научный оборот данные термины были введены в 2004 году.

Сегодня, кроме аудио- и видеоподкастов, выделяется еще одна разновидность - скринкаст, которую исследователи определяют как «видеоконтент с записью происходящего на экране компьютера, сопровождаемый комментариями автора. Скринкаст включает в себя текст, аудиоматериалы, а также движения курсора мыши». (Жабина, Сувирова 2019: 129-130).

Изначально сервис подкастов рассматривался в качестве альтернативного способа подачи информации для людей с аудиальным типом восприятия. Однако в последние годы подкасты находят широкое применение в образовании, особенно в обучении иностранным языкам. Вопросам использования данного сервиса в преподавании иностранных языков, анализу его дидактических характеристик и возможностей развития с его помощью определенных компетенций посвящены работы П. В. Сысоева, Н. М. Евстигнеева, Н. Г. Протазановой, А. Г. Соломатиной, Е. Д. Лазицкой, О. А. Колмаковой, Н. А. Игнатенко и др. Тем не менее методика работы с данным сервисом разработана не до конца. Обучение в «подосфере» (т.е. обучение с использованием подкастов) - инновационное направление современной методики преподавания иностранных языков.

Исследователи (П. В. Сысоев, Т. Л. Ступина, Т. В. Сапух) выделяют следующие дидактические характеристики подкастов: аутентичность, актуальность, автономность, мобильность, многофункциональность, интерактивность, продуктивность и др. Указанные характеристики позволяют говорить о данном сервисе как о перспективном дидактическом средстве обучения иностранным языкам.

Социальный сервис подкастов - один из самых быстроразвивающихся интернет-сервисов. Стабильно высокий интерес к подкастам и постоянный рост как числа слушателей, так и создателей материалов (подкастеров) обусловлен прежде всего актуальностью и остротой проблемы, поднимаемой в них. 
Именно это, на наш взгляд, отличает подкасты от других цифровых аудио- и видеотекстов в содержательном плане. На сегодняшний день в распоряжении слушателей имеется значительное число ресурсов, разнообразных по тематике и жанровой принадлежности (новостные, спортивные, научно-популярные, образовательные подкасты, интервью, радио-шоу и т.д.). Такое разнообразие обеспечивает вариативность содержания обучения.

Подкаст используется как средство обучения аудированию и говорению. Последнее актуализируется в процессе обсуждения учащимися полученной информации, а также при создании их собственных подкастов. Таким образом, в обучении иностранным языкам сервис подкастов может использоваться двумя способами: 1) прослушивание / просмотр информации и 2) создание собственных информационных продуктов (Сапух 2016).

В зависимости от целевой аудитории подкасты подразделяются на две группы: аутентичные (созданные для носителей языка) и учебные (созданные для учебных целей) (Сысоев 2014: 189). Учебные подкасты при этом могут создаваться как носителями, так не носителями языка, в частности студентами в процессе изучения неродного языка.

Естественно, наибольшее распространение подкасты получили в преподавании романо-германских языков, прежде всего английского языка. Для обучения данным языкам доступна целая база бесплатных подкастов (учебных и аутентичных), адресованных слушателям с разным уровнем подготовки. При этом к подкастам обычно прилагаются текстовые варианты (скрипты), некоторые платформы также предлагают проверочные задания. В преподавании русского языка как неродного роль и возможности подкастов, как отмечают исследователи (Ю. И. Савостьянова, Ю. Н. Сичинава), описаны еще недостаточно. Данная проблема становится еще более актуальной в обучении русскому языку как инославянскому. Нами не было обнаружено ни одного подкаста для славянской аудитории. Все прослушанные подкасты, предназначенные для обучения русскому языку, особенно на начальном уровне, сопровождаются переводом на английский язык. На английском языке осуществляется комментирование и изложение грамматического материала, что значительно затрудняет использование данного сервиса в работе с сербскими студентами, начинающими изучать русский язык.

В связи с этим наше внимание сосредоточено на аутентичных подкастах. Необходимость использования при обучении иностранному языку, в частности аудированию, аутентичных текстов не подлежит сомнению. Учащиеся, как справедливо отмечает П. В. Сысоев, «должны получить возможность услышать, кроме речи и акцента своего преподавателя, речь носителей языка» (Сысоев 2014: 192). Особенно это актуально на продвинутом этапе обучения, предполагающем умение общаться в условиях реальной языковой среды. Поскольку большинство студентов, изучающих русский язык в Сербии, говорят и воспринимают информацию на изучаемом языке главным образом во время учебных занятий, использование подкастов в дополнение к основной программе необходимо для совершенствования их коммуникативной компетенции.

Помимо разнообразного исполнения, характеризующегося различными фонационными особенностями (акцент, тембр, темп, сила голоса, интонация), 
подкасты предоставляют актуальную и интересную информацию, отражающую реальную действительность и особенности национальной культуры, что способствует углублению социокультурных знаний обучающихся. При этом, в отличие, например, от фильмов подкасты менее продолжительны по времени, визуальный ряд в них (если вообще присутствует) играет второстепенную роль и не отвлекает от содержания речи. Кроме того, как отмечает Н. А. Игнатенко, «отрывочность и, нередко, ненормативность реплик персонажей <фильма> могут мешать восприятию, а наличие субтитров слишком часто превращает самостоятельное аудирование без контроля преподавателя в «банальное» считывание реплик с экрана, нередко даже на языке перевода» (Игнатенко 2016: 151).

При выборе подкастов необходимо учитывать прежде всего авторитетность и компетентность сайта, достоверность и надежность информации, её актуальность и степень новизны, соответствие нормам русского языка. В связи с этим наше внимание обращено главным образом на радио-подкасты. Как известно, к речи радиоведущих предъявляются серьёзные требования, в том числе чёткое, ясное и нормативное произношение, информационная точность и выразительность. Одна из задач радио (и телевидения) - нести в широкие массы высокую культуру языка (Зарва 2011). При этом, как отмечают исследователи, радиокоммуникация характеризуется естественностью и эмоциональностью. Опосредованным адресатом такой коммуникации является радиослушатель, в нашем случае - студент, который вольно или невольно вовлекается в беседу, анализирует услышанное и формулирует свою позицию. Нередко в радиопередачах используется диалогическая речь с её аутентичными дискурсивными особенностями, овладение которыми является одной из важнейших задач обучения иностранному языку (Игнатенко 2016: 151).

Еще одним критерием выбора подкаста является его соответствие содержанию обучения и будущим профессиональным интересам студентов. Учитывая тот факт, что Департамент русского языка и литературы Философского факультета Университета в Нише готовит будущих филологов неродного языка, нас заинтересовали прежде всего подкасты, поднимающие важные языковые проблемы и рассматривающие особенности функционирования русского языка в современных социокультурных условиях, подкасты о русской культуре и литературе. Так, подкаст радио «Маяк» «Как стать русским?» в одной из передач обсуждает такие проблемы русского языка, как формы обращений и приветствий, языковая мода и т.д., а также влияние зарубежных, советских и современных отечественных мультфильмов на подрастающее поколение. Подкаст «Медузы» «Розенталь и Гильденстерн» задает очень актуальный вопрос: «как коронавирус меняет русский язык?». Подкасты портала «Культура РФ» предлагают ознакомиться с разнообразными фактами истории, литературы, культуры и искусства нашей страны. При этом отдельные подкасты портала «Культура РФ» или их фрагменты могут быть использованы не только при изучении тех или иных разговорных тем, но и как дополнение к программам по русской литературе и культуре.

Работа с подкастом, как и с другими аудиоматериалами, осуществляется в три этапа: преддемонстрационный (предтекстовый, подготовительный), демонстрационный (текстовый) и последемонстрационный (послетекстовый). В 
учебное время такая трехэтапная работа может быть проведена при условии использования подкастов, непродолжительных по времени, или отдельных аудиофрагментов. Если длительность подкаста составляет более 15 мин., то его прослушивание (демонстрационный этап) обычно проходит во внеучебное время. При самостоятельном прослушивании подкастов студент, используя специализированные программы, может регулировать темп речи говорящего и выстраивать свою работу с аудиоматериалом в зависимости от скорости его восприятия.

Рассмотрим этапы работы на примере научно-популярного подкаста о русском языке и лингвистике «Розенталь и Гильденстерн» на тему «Инфодемия, коронарка, санитайзер и самоизоляция: как коронавирус меняет русский язык?» (https://meduza.io/episodes/2020/03/23/infodemiya-koronarka-sanitayzeri-samoizolyatsiya-kak-koronavirus-menyaet-russkiy-yazyk; https:/www.youtube. com/watch?v=gnr-c6BTstI).

Подготовительный (преддемонстрационный) этап - это этап введения в тему, этап психологической и языковой подготовки к восприятию подкаста. В первую очередь необходимо обратить внимание студентов на название подкаста и объяснить его происхождение, тем самым подготовить их к обсуждению лингвистических проблем. Стоит отметить, что в качестве эксперта в подкасте выступает главный редактор портала «Грамота.ру», научный сотрудник Института русского языка РАН Владимир Пахомов.

Одним из эффективных способов, актуализирующих уже имеющиеся у студента знания по теме, является составление ассоциограмм, т.е. графическая или словесная запись ассоциаций, связанных с изучаемым явлением или понятием. Так, в работе с указанным выше подкастом одно из заданий предполагает составление свободной круговой ассоциограммы, связанной с понятием коронавирус. Альтернативой данному заданию может быть использование заранее подготовленной инфографики или облака тегов с последующим анализом ключевых слов. После этого студентам предлагается составить список новых слов, вошедших в русский язык в связи с распространением коронавируса, и после прослушивания подкаста сравнить свой список со словами, упомянутыми экспертами.

Для снятия возможных лексических и грамматических затруднений перед прослушиванием выполняются задания, связанные с объяснением значений некоторых слов и выражений, с соотнесением понятий и их определений. К числу таких заданий относятся следующие:

1. Соотнесите понятия в левом столбце с их определениями в правом столбце:

1. Мещанство А. то же, что дезинформация; ложные, ошибочные данные

2. Триггер

Б. поведение, деятельность людей, несогласных с

3. Ажиотаж
4. Деза (разг. господствующей в стране идеологией; инакомыслие

В. критически-недоверчивое отношение к чему-либо

4. Деза (разг.)

Г. сильное возбуждение, волнение с целью привлечения

5. Перебои внимания к чему-либо

Д. явление, приводящее какой-либо процесс в действие 
7. Диссидентство Ж. периодически повторяющаяся задержка, приостановка

2. Дайте определение следующим словам и выражениям: скептик, диссидент, вирусолог, политолог; порт, судно, встать на якорь; молниеносно, неотвратимо; понурый.

3. Сравните слова корона и коронка. Обратите внимание на наличие у слова коронка дополнительного значения: металлическая оболочка, накладываемая на испорченный зуб с целью его сохранения.

4. Соотнесите глагол и действие, которое он называет:
1. Колебаться
A. покупать в больших количествах
2. Коробить
Б. быть неустойчивым, меняться
3. Скупать
B. острым предметом наносить тонкие борозды на поверхность или разрывать её
4. Царапать
Г. производить неприятное впечатление, отталкивать

Рассматриваемый подкаст затрагивает целый ряд собственно лингвистических вопросов, позволяющих актуализировать знания студентов по профильным дисциплинам: основное и побочное ударение, способы образования новых слов, орфографические правила. Поэтому уместным перед прослушиваем считаем включение таких заданий, как:

- Назовите слова, в которых есть побочное ударение.

- Назовите продуктивные способы образования новых слов.

- Каким способом образованы следующие слова: маршрутка, молочка, ювелирка? От каких слов они образованы?

Образуйте разговорные сокращённые слова от следующих словосочетаний:

электрический поезд -

открытое письмо -

кондитерские изделия -

элитная продукиия -

Лазурный берег -

удалённая работа -

запрешённая продукичи -

санкционная продукиия -

- Какие из образованных вами слов являются сегодня неологизмами? 
- Вспомните правило правописания $b$ и $u$ после приставок и вставьте пропущенные буквы:

Пред...стория, об...играть, под..тожить, с..митировать, дез...формация, дез...нфекиия, контр ...гра, пост...мпрессионизм, супер...нфекиия.

В случае необходимости на подготовительном этапе преподаватель комментирует упоминаемые в подкасте факты, события, персоналии или дает другую информацию, обязательную для адекватного понимания материала. Применительно к подкасту «Розенталь и Гильденстерн» требуется пояснить, как работает Национальный корпус русского языка (http://www.ruscorpora.ru/ new/), а также объяснить роль и значение акции «Тотальный диктант».

Следующий этап (демонстрационный) включает задания, выполняемые во время прослушивания. Учитывая длительность подкаста (31 мин.) целесообразно прослушивать его фрагментами.

В соответствии с разными видами аудирования прослушивание подкастов может быть направлено на полное понимание содержания, на понимание основного содержания, на выборочное извлечение информации, критическую оценку информации и выражение собственного мнения (Лазицкая, Колмакова 2013: 288).

Рассматриваемый подкаст предполагает полное понимание его содержания и поиск конкретной языковой информации. Студентам предлагается ответить на следующие вопросы:

1. Почему слово коронавирус пишется с буквой $a$ в середине? Каково происхождение слова? Как раньше писалось это слово?

2. Можно ли заболеть коронавирусом с точки зрения строгих норм русского литературного языка?

3. Какие разговорные эквиваленты появились у слова коронавирус?

4. Какое новое слово использовал пресс-секретарь Дмитрий Песков?

5. Как вы понимаете слова корона-скептик и корона-диссидент?

6. Отправить в карантин или на карантин? Вернуться из карантина или $c$ карантина? В чём различие в употреблении предлогов в и на?

7. Какова этимология слова карантин? Первый пример употребления этого слова относится к 1940 г. Изменилась ли сегодня оценка этого слова?

8. Что такое инфодемия?

9. Чем различается произношение слов эпидемия, инфодемия и пандемия и почему?

10. Чем различается произношение слов дезинфекичия и дезинформация и почему?

11. Чем различается произношение слов термос и термин?

12. Объясните правописание слов инфекциия и инфициировать.

13. Какие сокращённые слова появились в русском языке с 2014 г.?

14. Как носители языка оценивают сокращённые слова? Меняется ли их оценка со временем? 
15. Не запрещёнкой единой: как в оригинале звучит данное выражение?

16. Заполните пропуски и найдите отличия в речи москвичей и петербуржцев:

В Москве пустеют улицы, а также пустеют аптеки,

и нет в магазинах ..., и нет в магазинах ...

И в Питере тоже не легче, и люди тоже понуры,

ведь нет в магазинах ..., и нет в магазинах ...

Последний (последемонстрационный) этап может включать различные типы заданий: репродуктивные, частично-продуктивные и продуктивные (творческие) в зависимости от языковой подготовки учащихся (Карева 2014: 140). В связи с тем, что обычно в одной группе учатся студенты с разным уровнем владения языком, мы предлагаем как репродуктивные, так и творческие задания. К первому типу относится, например, задание, в котором необходимо определить, верны или неверны следующие утверждения:

1. Корона-скептики и корона-диссиденты - это группа людей, которые либо не верят в существование нового вируса или полагают, что проблема на самом деле не такая большая, как её представляют СМИ и политики.

2. Коронарка - это заболевание сосудов сердца.

3. Ковид, корона, коронка - разговорные эквиваленты слова коронавирус.

4. Слово карантин переводится с итальянского как 40 дней и ночей.

5. Понятие самоизоляциия первоначально использовалось в психологии с негативной оценкой.

6. Слова пандемия, инфодемия, дезинфекичия и дезинформациия произносятся с твёрдым согласным [д].

7. Инфодемия - это распространение ложной информации, слухов и домыслов об эпидемии.

В качестве творческого задания мы предлагаем студентам обсудить следующие вопросы: Отмечаются ли аналогичные явления в сербском языке? Что произойдёт с этими новыми словами в будущем? Какие из них останутся в языке, а какие выйдут из употребления?

Таким образом, социальный интернет-сервис подкастов является одним из перспективных средств развития иноязычной коммуникативной компетенции. Подкаст как источник аутентичной звучащей речи обеспечивает кратковременное погружение обучающихся в иноязычную среду, что способствует преодолению языкового барьера и осуществлению межкультурной коммуникации. Студенты слушают живую разговорную речь, причем речь литературную, грамотную, обсуждают актуальные проблемы и отвечают на вопросы - всё это совершенствует их навыки аудирования и говорения, обогащает лексический запас, развивает когнитивные способности, а также стимулирует к дальнейшему самостоятельному изучению языка. 


\section{Использованная литература}

Жабина, Людмила В., Анастасия Ю. Сувирова. «Использование скринкастов в работе преподавателя иностранного языка и в проектной работе студентов вузов по направлению «Реклама и связи с общественностью»». Общество: социология, психология, педагогика 3/59, 2019: 129-133.

[Zhabina, Lyudmila V., AnastasiâY. Suvirova. «Ispol'zovanie skrinkastov v rabote prepodavatel'â inostrannogo âzyka I v proektnoy rabote studentov vuzov po napravleniyu "Reklama i svâzi s obschestvennost'u"». Oschestvo: sotsiologiâ, psikhologiâ, pedagogika 3/59, 2019: 129-133]

Зарва, Майя. В. Слово в эфире: О языке и стиле радиопередач: Произношение в радио- и телевизионной речи. Москва: Флинта: Наука, 2011.

[Zarva, Maya. V. Slovo v efire: O âzyke i stil'e radioperedach: Proiznosheniye v radio- i televizionnoy rechi. Moskva: Flinta: Nauka, 2011]

Игнатенко, Наталья А. «Подкасты англоязычного радио в самостоятельной работе студентов на продвинутом этапе обучения иностранному языку». Язык и культура 1/33, 2016: $148-159$.

[Ignatenko, Natal'â A. «Podkasty angloyazichnogo radio v samostoyatel'noy rabote studentov na prodvinutom etape obucheniya inostrannomu âziku». Yazyk i kul'tura 1/33, 2016: 148-159.]

Карева, Наталья В. «Использование аутентичных аудио и видео материалов для повышения мотивации изучения иностранного языка». Вестник евразийской науки 3/22, 2014: 140.

[Kareva, Natal'â V. «Ispol'zovanie autentichnykh audio i video materialov dlya povysheniâ motivatsii izucheniâ inostrannogo âzyka». Vestnik evroaziyskoy nauki 3/22, 2014: 140.]

Лазицкая, Елена Д., Ольга А. Колмакова. «Методика работы с подкастами при организации внеаудиторной деятельности студентов». Вестник Иркутского государственного технического университета 9/80, 2013: 285-289.

[Lazitskaya, Elena D., Ol'ga A. Kolmakova. «Metodika raboty s podkastami pri organizatsii vneauditornoy deyatel'nosti studentov». Vestnik Irkutskogo gosudarstvennogo tekhnicheskogo universiteta 9/80)ж, 2013: 285-289.]

Протазанова, Наталья Г. «Использование социального сервиса подкастов в обучении иностранным языкам». Ярославский педагогический вестник 3, Т. ІІ, 2011: 95-97.

[Protazanova, Natal'â G. «Ispol'zovanie sotsial'nogo servisa podkastov v obuchenii inostrannym âzykam». Yaroslavskiy pedagogicheskiy vestnik 3, T. II, 2011: 95-97.]

Савостьянова, Юлия И., Юлия Н. Сичинава. «Интеграция системы языковых подкастов в учебный процесс военного вуза». Теория и практика общественного развития 14, 2014: 35-38.

[Savost'yanova, Yuliâ I., Yuliâ N. Sichinava. «Integratsiâ sistemy âzykovykh podkastov v uchebniy process voennogo vuza». Teoriâ i praktika obschestvennogo razvitiya 14, 2014: 35-38.]

Сапух, Татьяна В. «Развитие иноязычной коммуникативной компетенции бакалавров посредством подкастов». Азимут научных исследований: педагогика и психология 3 (16), Т. 5, 2016: $150-153$.

[Sapukh, Tat'âna V. «Razvitie inoâzychnoy kommunikativnoy kompetentsii bakalavrov posredstvom podkastov». Azimut nauchnykh issledovaniy: pedagogika i psikhologiâ 3 (16), T. 5, 2016: $150-153$.

Сысоев, Павел В. «Подкасты в обучении иностранному языку». Язык и культура 2 (26), 2014: 189-201.

[Sysoev, Pavel V. «Podkasty v obuchenii inostrannomu âzyku». Yazyk i kul'tura 2 (26), 2014: 189-201.] 
Олга Трапезњикова

\title{
КОРИШЋЕЊЕ ПОДКАСТОВА У НАСТАВИ РУСКОГ ЈЕЗИКА КАО ИНОСЛОВЕНСКОГ
}

\begin{abstract}
Резиме
У раду се разматрају могућности коришћења друштвеног интернет-сервиса подкастова у настави руског језика као инословенског, описују се предности ове технологије у развоју комуникативних компетенција студената на страном језику, као и карактеристике њене примене у процесу учења другог словенског језика. Узимајући у обзир, са једне стране, недостатак специјализованих образовних подкастова у области руског језика за носиоце других словенских језика, а са друге одређену блискост матерњег и нематерњег језика студената, сврсисходно је да се у условима рада са таквим студентима на напредној етапи користе аутентични подкастови. Подкаст као извор аутентичног говора ствара илузију природне језичке средине и омогућава да се рад са студентима организује на нов начин, усмерен на усавршавање вештина слушања и изговарања. Недостатак формалних обавеза у подкастовима, као и контроле придржавања језичких норми, а такође и велика разноврсност ресурса који су у садашње време доступни студентима, условљавају потребу за израдом методичких упутстава за избор подкастова ради одређених наставних циљева и конкретних слушалаца, те планирање система рада са овим ресурсом. У овом истраживању се предлаже систем рада са подкастовима за српске студенте, који владају руским језиком на напредном нивоу.
\end{abstract}

Кључне речи: подкаст, руски језик као инословенски, аудирање, говорење, комуникативна компетенција студената на страном језику. 